.

\title{
Environmental impact ratings that could drive positive environmental changes in the manufacture and use of pharmaceuticals
}

\author{
Amelia Cussans ${ }^{1}$, Guy Harvey ${ }^{2}$, Terry Kemple ${ }^{3 *}$, Tracy Lyons ${ }^{4}$, Mike Tomson $^{5}$, \\ Angela Wilson ${ }^{6}$
}

${ }^{1}$ Psychiatry Trainee, Central North West London NHS Trust Mental Health Centre, London, UK; ${ }^{2}$ Member of the RCPsych Planetary Health and Sustainability Committee. Consultant Psychiatrist, Cumbria Northumberland Tyne and Wear NHS Trust, Newcastle upon Tyne, UK; ${ }^{3}$ Royal College of General Practitioners National Representative for Sustainability, Climate Change and Green Issues, Lead for Green Impact for Health Toolkit, Executive member of UK Health Alliance for Climate Change, London, UK; ${ }^{4}$ Medicines Optimisation Pharmacist, Directorate Sustainability Lead, Radiology \& Pharmacy, University Hospital Dorset NHS Foundation Trust, Poole, UK; ${ }^{5}$ Retired GP, Sheffield, UK; ${ }^{6}$ Locum, Oxfordshire Clinical Commissioning Group, UK

*For correspondence: tjkemple@gmail.com

Competing interest: The authors declare that no competing interests exist.

Received: 12 November 2021 Accepted: 13 December 2021 Published: 12 January 2022

(C)This article is Open Access: CC BY license (https://creativecommons.org/licenses/by/4.0/)

Author Keywords: environment, Quality assurance, pharmaceuticals, general practice, primary healthcare

Copyright (C) 2022, The Authors; DOI:10.3399/BJGPO.2021.0214
The climate and ecological emergency (CEE) is the greatest health threat of the $21^{\text {st }}$ century. ${ }^{1}$ Many clinicians work hard to reduce their personal carbon footprint. This contrasts with our work lives, where we have limited scope to reduce the environmental impact of the care we provide. Our priorities lie in delivering the best possible care to the patients in front of us, so this dissonance often goes unaddressed. Yet paradoxically our services may contribute to climate-related health hazards. We will all feel the impacts of the CEE, but the health burden will impact most on future generations ${ }^{2}$ and lowincome, minority and politically-marginalised groups. ${ }^{3}$ This is a matter of global and intergenerational justice. All industries have a moral obligation ${ }^{4}$ to reduce their carbon emissions, and as an organisation dedicated to protecting public health, the NHS has an imperative to do so.

The pharmaceutical industry plays a central role in health care, yet it is also an area of growing concern. Globally, its emissions intensity is $55 \%$ higher than the automotive sector. ${ }^{5}$ The supply chain $^{6}$ - pharmaceuticals and medical instruments — contributes the highest proportion of the NHS's greenhouse gas (GHG) emissions. Given that the NHS produces $4 \%$ of the UK's total GHG emissions, ${ }^{6}$ pharmaceuticals are a major contributor to the climate crisis. Indeed, in primary care, medicines have been identified as a 'carbon hotspot', accounting for $65 \%$ of its total GHG emissions.'

In addition to their global warming potential, human and veterinary pharmaceuticals have wideranging environmental impacts. They are released into natural systems during manufacture, use, and disposal, even following excretion by the patient. Drugs accumulate in water sources where they can have toxic effects on aquatic ecosystems. ${ }^{8}$ The body of evidence for this is mounting. Non-steroidal anti-inflammatory drugs (NSAIDs) have been found in otter fur. ${ }^{9}$ Hormonal contraceptives disrupt frog fertility. ${ }^{10}$ Venlafaxine can cause freshwater snails ${ }^{11}$ to detach from surfaces. Citalopram reduces predator avoidance behaviours in crayfish. ${ }^{12}$ These drugs enter the food chain and ultimately make their way back to humans; the health impacts of this remain unknown.

Based on 'first do no harm' it is essential that we act quickly and collectively to mitigate the environmental impact of pharmaceuticals. Our General Practitioners, Psychiatrists and Pharmacists Working Group has focused on how we can reduce the environmental impact of pharmaceuticals from 
research, manufacture, packaging, and sterilisation, through to transport, consumption, elimination, and disposal. Improving our prescribing practices through medicines optimisation is key to making pharmaceuticals more sustainable, although this is beyond our scope here.

We know there is great variation in drug companies' environmental performance. All other things being equal, clinicians and patients prefer to use the least polluting medications. But it would be hard for clinicians to factor in the green credentials of each pharmaceutical to every prescribing decision. Nor would it be feasible to undertake carbon calculation for each individual drug. Instead, the NHS could categorise manufacturers based on their progress towards environmental commitments. Drugs could then be procured preferentially from companies with the best green performance.

Our working group proposes an Environmental Impact Rating (EIR) system for NHS pharmaceutical manufacturers, based on the environmental impact of their products. The EIR would consider the entire pharmaceutical lifecycle. This covers manufacture, sterilisation, packaging, and waste products.

\begin{tabular}{|c|c|}
\hline White & $\begin{array}{l}\text { No plan } \\
\text { OR no information provided }\end{array}$ \\
\hline Red & $\begin{array}{l}\text { Stated commitment only } \\
\text { OR draft plan } \\
\text { OR full plan which does not meet NHSE net zero targets }\end{array}$ \\
\hline Amber & Detailed plan which meets NHSE net zero targets \\
\hline Green & $\begin{array}{l}\text { Detailed plan which meets NHSE net zero targets } \\
\text { AND plan will result in achievement of net zero before } 2030 \\
\text { AND has actively supported research on the potential ecotoxicity of } \\
\text { their product portfolio and has shared all available research outcomes }\end{array}$ \\
\hline $\begin{array}{l}\text { Meets NHS } \\
\text { Standards }\end{array}$ & $\begin{array}{l}\text { Detailed plan which meets NHSE net zero targets } \\
\text { AND plan will result in achievement of net zero before } 2030 \\
\text { AND has actively supported research on the potential ecotoxicity of } \\
\text { their product portfolio and has shared all available research outcomes } \\
\text { AND plan has been independently audited by carbon accountants }\end{array}$ \\
\hline
\end{tabular}

Figure 1 NHS England manufacturer Environmental Impact Rating (EIR) status categories 
Stages that take place outside of the UK must be accounted for. All four of the UK nations have committed as part of the UK COP26 Presidency's Health Programme to become net zero health services. The NHS England (NHSE) net zero plan commits to carbon neutrality by 2040 for direct and by 2045 for indirect emissions, which includes the supply chain. In the NHSE plan, pharmaceutical companies will have to match these environmental commitments to continue to supply the NHSE with drugs after 2030. We believe in an earlier net zero target in line with the current climate science, ${ }^{13}$ which states that we need to be more ambitious ${ }^{14}$ to mitigate the worst effects of climate change. The EIR rating asks for data on ecotoxicity as well as GHG emissions because a drug could theoretically be carbon-neutral yet still a potent eco-toxin.

We propose a traffic light EIR rating system with categories that could look like Figure 1.

The NHSE should reward manufacturers with the least environmental impact by preferentially purchasing their products. Any excess cost could be limited. For example, if the acceptable price difference between each of the 5 EIR rankings was set at $10 \%$ of the cost of the cheapest product, then the cheapest product from the manufacturer with the worst environmental impact could be purchased if the product from the manufacturer with the least environmental impact cost $40 \%$ more than the cheapest. This system would create a competitive advantage for companies who achieve zero carbon early, actively encouraging them to improve their environmental performance. Ultimately, we want all manufacturers to achieve these standards in all UK nations as soon as possible. This would accelerate the NHS's journey towards net zero. ${ }^{6}$

Manufacturers should publish transparent and detailed plans, including calculations of current and projected carbon emissions. Their plans should be accompanied by a separate report from independent carbon auditors. This should include a robustly measured carbon footprint and comments on the strength and credibility of the manufacturer's plan. This would reduce the risk of greenwashing. There are a number of carbon accounting services available and these services are expected to grow as demand increases. The NHSE would need to establish which methodology can reliably be used so that reports are comparable. Manufacturers' compliance with their plans should be subject to annual audits to calculate current footprints and to ensure they are meeting their targets.

An area that requires further consideration is how this system should appraise and factor in the impact of specific products. For example, Salamol inhalers contain half as much hydrofluorocarbon propellant ${ }^{15}$ as Ventolin inhalers for an equivalent dosage, halving their carbon footprint. Data of this nature will need to be considered as well as the green credentials at a company level.

In time, we hope meeting these standards will be tied to legislative requirements. It is worth noting that legal experts worldwide are seeking to make 'ecocide' an international crime ${ }^{16}$ within the jurisdiction of the International Criminal Court. A definition of ecocide has recently been unveiled: 'unlawful or wanton acts committed with knowledge that there is a substantial likelihood of severe and widespread or long-term damage to the environment being caused by those acts'. If adopted by the International Criminal Court then corporations, including those manufacturing pharmaceuticals, could be prosecuted for serious offences against the environment. We hope this may be a catalyst for faster change.

The Delivering a 'Net Zero' National Health Service ${ }^{6}$ report states 'the NHS has a responsibility to use its purchasing power to drive positive environmental, social and economic change and add value for the communities it serves'. Our Working Group believes the EIR is a viable intervention which would allow doctors and patients to be confident that the medicines they use are from the greenest manufacturers.

Funding

N/A

Ethical approval

N/A

Provenance

Freely submitted; extrnally peer reviewed.

Acknowledgements

N/A 


\section{References}

1. Watts N, Amann M, Arnell N, et al. The 2019 report of the Lancet Countdown on health and climate change: ensuring that the health of a child born today is not defined by a changing climate. Lancet 2019; 394(10211): 1836-78. DOI: https://doi.org/10.1016/S0140-6736(19)32596-6

2. Hansen J, Kharecha P, Sato M, et al. Assessing "dangerous climate change": required reduction of carbon emissions to protect young people, future generations and nature. PLoS One 2013; 8(12): e81648. DOI: https:// doi.org/10.1371/journal.pone.0081648

3. Islam SN, Winkel J, United Nations. Climate Change and Social Inequality. 2017; https://www.un.org/en/desa/ climate-change-and-social-inequality (accessed 17 Dec 2021).

4. Richie C. Environmental sustainability and the carbon emissions of pharmaceuticals. J Med Ethics 14 2021: medethics-2020-106842. DOI: https://doi.org/10.1136/medethics-2020-106842

5. Belkhir L, Elmeligi A. Carbon footprint of the global pharmaceutical industry and relative impact of its major players. Journal of Cleaner Production March 2019; 214: 185-94. DOI: https://doi.org/10.1016/j.jclepro.2018.11. 204

6. Greener NHS. Delivering a 'Net Zero' National Health Service. 2020; https://www.england.nhs.uk/greenernhs/wpcontent/uploads/sites/51/2020/10/delivering-a-net-zero-national-health-service.pdf (accessed 17 Dec 2021).

7. British Medical Association. Sustainable and environmentally friendly general practice: GPC England Policy Document. 2020; https://www.bma.org.uk/media/2570/bma-sustainable-and-environmentally-friendly-generalpractice-report-june-2020.pdf (accessed 17 Dec 2021).

8. Mezzelani M, Gorbi S, Regoli F. Pharmaceuticals in the aquatic environments: evidence of emerged threat and future challenges for marine organisms. Mar Environ Res 2018; 140: 41-60. DOI: https://doi.org/10.1016/j. marenvres.2018.05.001

9. Richards NL, Cook G, Simpson V, et al. Qualitative detection of the NSAIDs diclofenac and ibuprofen in the hair of eurasian otters (lutra lutra) occupying UK waterways with GC-MS. Eur J Wildl Res 2011; 57(5): 1107-14. DOI: https://doi.org/10.1007/s10344-011-0513-2

10. Säfholm M, Norder A, Fick J, et al. Disrupted oogenesis in the frog xenopus tropicalis after exposure to environmental progestin concentrations. Biol Reprod 2012; 86(4): 126. DOI: https://doi.org/10.1095/biolreprod. 111.097378

11. Fong PP, Molnar N. Antidepressants cause foot detachment from substrate in five species of marine snail. Mar Environ Res 2013; 84: 24-30. DOI: https://doi.org/10.1016/j.marenvres.2012.11.004

12. Reisinger AJ, Reisinger LS, Richmond EK, et al. Exposure to a common antidepressant alters crayfish behavior and has potential subsequent ecosystem impacts. Ecosphere 15 June 2021; 12(6): e03527. DOI: https://doi.org/10. 1002/ecs2.3527

13. Carbon Brief. Future climate projections: five graphs from three reports. 2012; https://www.carbonbrief.org/futureclimate-projections-five-graphs-from-three-reports (accessed 17 Dec 2021).

14. UN Environment Program. Emissions Gap Report 2020. 2020; https://www.unep.org/emissions-gap-report-2020 (accessed 17 Dec 2021).

15. Berkshire West Integrated Care Partnership. Reducing the environmental impact of inhalers [Prescribing Oversight Committee ClinDoc 059]. 2020; https://www.berkshirewestccg.nhs.uk/media/4209/poc-clindoc-059-reducing-theenvironmental-impact-of-inhalers.pdf (accessed 17 Dec 2021).

16. Stop Ecocide International. Stop Ecocide International. 2021; https://www.stopecocide.earth (accessed 17 Dec 2021). 